\title{
KAHDELLA ERI LANNOITUSTASOLLA VILJELTYJEN PERUNALAJIKKEIDEN LAATU RUOKAPERUNANA
}

\author{
Rakel Kurkela, Anita Ellala ja Lasse Vanhanen \\ Elintarvikekemian ja -teknologian laitos, Helsingin yliopisto
}

Saapunut 16. 7. 1971

\begin{abstract}
THE COOKING QUALITY OF SOME POTATO VARIETIES CULTIVATED IN TWO DIFFERENT LEVELS OF FERTILIZATION
\end{abstract}

\begin{abstract}
The cooking quality of 14 different potato varieties was investigated. The varieties were Dore, Ersteling, Ostara, Siikkli, Sirtema, Tanja (early potatoes) and Alfa, Bintje, Milva, Patrones, Realta, Rekord and Tombola (late potatoes). Every variety was cultivated in two different levels of fertilization; the so-called normal fertilization was $75 \mathrm{~kg}$ $\mathrm{N} / \mathrm{ha}, 200 \mathrm{~kg} \mathrm{~K} 2 \mathrm{O} / \mathrm{ha}, 190 \mathrm{~kg} \mathrm{P}_{2} \mathrm{O}_{5} / \mathrm{ha}$, while the richer one was double compared to the former. Mealiness and flavour were evaluated from the samples fractioned into five specific gravity classes. On the basis of sensory evaluation of the different classes the amount of potatoes of high quality was calculated from all the samples. The mealiness and flavour of the potatoes representing the specific gravity class of highest total weight were considered characteristic to the sample. The specific gravity, darkening after cooking and the keeping quality of prepeeled potatoes, were also regarded as criteria of the quality. Increased fertilization decreased the mean specific gravity of every variety. The amount of high qualitypotatoes varied $0-28 \mathrm{tn} /$ ha depending on the variety and the application of fertilization. Increased fertilization increased the amount of high quality potatoes of early varieties but decreased the amount of high quality potatoes of later varieties. Sloughing was a problem only with Milva, which makes difficult its use in a normal way. Prepeeled potatoes stayed unblackened $1-5$ days depending on the variety. The keeping quality was not affected by fertilization. The effect of increased fertilization on the flavour was studied by comparing the potatoes of the same specific gravity grown on normal fertilization with those grown on a richer one by triangle tests. Fertilizing affected noticable difference in the flavour of the varieties Siikli, Tanja, Realta and Patrones but not in the other varieties.
\end{abstract}

Teollisuusruokaperunan tuotantomahdollisuuksia Kaakkois-Suomessa tutkittiin ItäSuomen Raakasokeritehdas Oy:n toimesta kesällä 1968. Viljelykokeilla selvitettiin mm. eri typpi- ja kalilannoiteyhdistelmien vaikutusta Realtan ja Bintjen satoisuuteen ja sadon laatuun (Ellala ym. 1971). Samassa yhteydessä koeviljeltiin kahdella eri lannoitustasolla 14 eri perunalajiketta. Ruokaperunakelpoisuuden osalta tutkimukset tehtiin yliopiston elintarvikekemian ja -teknologian laitoksella.

\section{Materiaali ja menetelmät}

Lajikkeet. Kokeissa olivat varhaisperunalajikkeina Dore, Ersteling, Ostara, Siikli, Sirtema ja Tanja sekä talviperunalajikkeina Bintje, Milva, Patrones, Realta, Rekord 
ja Tombola. Niiden lajikkeiden osalta, joista siementä ei ollui saatavissa Suomesta, käytettiin Hollannista ja Tanskasta hankittua siementä. Käytetty siemen oli tasalaatuista ja virustestattua.

$\mathrm{K}$ asvupaikka ja lannoitus. Perunat viljeltiin Vehkalahdella, jossa maalaji oli hietainen urpasavi, kahdella eri lannoitustasolla. Ns. normaali lannoitus käsitti $75 \mathrm{~kg} \mathrm{~N} / \mathrm{ha}, 200 \mathrm{~kg} \mathrm{~K} 2 \mathrm{O} / \mathrm{ha}$ ja $190 \mathrm{~kg} \mathrm{P}_{2} \mathrm{O}_{5} / \mathrm{ha}$ eli lannoitemäärinä ilmoitettuna $300 \mathrm{~kg}$ Oulun salpietaria, $400 \mathrm{~kg}$ kaliumsulfaattia ja $1000 \mathrm{~kg}$ superfosfaattia hehtaaria kohti. Voimakkaalla lannoitustasolla edellä mainittu lannoitus oli kaksinkertaisena.

$\mathrm{K}$ a svuaika. Varhaisperunalajikkeiden kasvuaika oli 12 viikkoa ja talviperunalajikkeiden noin 15 viikkoa.

K o ejärjestelyt. Yksityiskohtaiset tiedot koejärjestelystä ja viljelytekniikasta käyvät selville Itä-Suomen Raakasokeritehdas Oy:n kenttäkokeita koskevasta raportista (Itä-Suomen Raakasokeritehdas Oy, 1968). Satotulokset on esitetty kuvassa 1. Tutkimuksia varten saatiin $50 \mathrm{~kg}: \mathrm{n}$ näyte kustakin lajikkeesta molemmilta lannoitustasoilta kokoluokkaa $35-55 \mathrm{~mm}$.
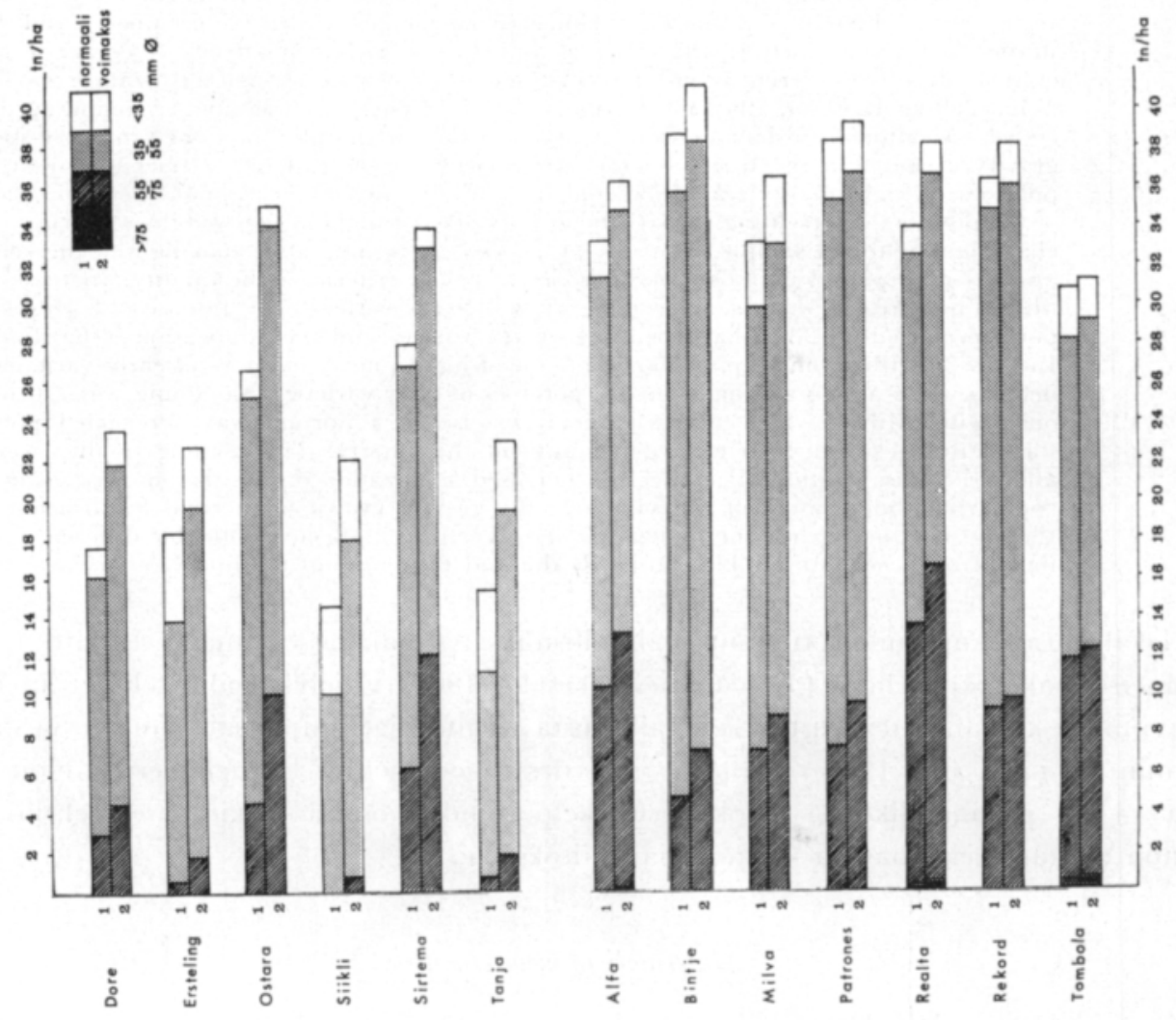

Kuva 1. Eri perunalajikkeiden sadot kokoluokittain normaalilla ja voimakkaalla lannoitustasolla. 
L a a d u n t e s t a us. Ominaispainojakauma, maku, jauhoisuus, moitteettoman ruokaperunan osuus, keitonjälkeinen tummuminen ja kuorittuna säilyvyys määritettiin samoilla menetelmillä kuin aikaisemmassa tutkimuksessa (Ellala ym. 1971). Rikkikiehuminen arvosteltiin 10:stä kuorineen vedessä keitetystä perunasta asteikolla: Täysin ehjä, melkein ehjä, hiukan rikki, rikki, täysin hajalla. Lannoituksen aiheuttamat makuerot tutkittiin triangelitestillä (Ellala ym. 1971).

\section{Tulokset}

Ominaispainojaka umat ja keskimä äriset ominaispainot on esitetty varhaisperunalajikkeiden osalta taulukossa 1 ja talviperunalajikkeiden osalta taulukossa 2. Kunkin lajikkeen ominaispainojakautumassa on painomäärältään suurin ominaispainoluokka alleviivattuna.

Taulukko 1. Eri varhaisperunalajikkeiden keskimääräiset ominaispainot ja ominaispainojakautumat. Painomäärältään suurin ominaispainoluokka alleviivattu taulukossa.

\begin{tabular}{|c|c|c|c|c|c|c|}
\hline Lajike & $\begin{array}{l}\text { Keski- } \\
\text { määräinen } \\
\text { om.p. }\end{array}$ & $<1065$ & $\begin{array}{l}1065- \\
1075\end{array}$ & $\begin{array}{l}1075- \\
1085\end{array}$ & $\begin{array}{l}1085- \\
1095\end{array}$ & $>1095$ \\
\hline & & $\%$ & $\%$ & $\%$ & $\%$ & $\%$ \\
\hline Dore $n^{1}$ ) & 1.093 & 2.5 & 9.3 & 39.1 & 44.5 & 5.5 \\
\hline Dore $v^{2}$ ) & 1.082 & 1.5 & 11.8 & $\underline{46.1}$ & 38.5 & 2.0 \\
\hline Ersteling n & 1.079 & 0.5 & 20.1 & 64.6 & 14.3 & 0.5 \\
\hline Ersteling $\mathbf{v}$ & 1.079 & 1.5 & 26.4 & 63.2 & 8.5 & 0.5 \\
\hline Ostara n & 1.070 & 16.4 & 53.3 & 28.8 & 1.4 & \\
\hline Ostara v & 1.069 & 14.8 & 65.0 & 19.5 & 0.6 & \\
\hline Siikli n & 1.079 & 0.5 & 25.0 & 59.4 & 15.1 & \\
\hline Siikli v & 1.076 & 3.6 & 42.3 & 50.0 & 4.1 & \\
\hline Sirtema $\mathrm{n}$ & 1.076 & 3.2 & 41.6 & 52.2 & 3.0 & \\
\hline Sirtema $\mathrm{v}$ & 1.071 & 10.7 & 61.4 & 27.9 & & \\
\hline Tanja $\mathrm{n}$ & 1.087 & 0.8 & 2.9 & 25.0 & 65.0 & 6.3 \\
\hline Tanja $\mathrm{v}$ & 1.081 & 1.3 & 13.9 & 57.4 & 27.4 & \\
\hline
\end{tabular}

1) $\mathbf{n}=$ normaali lannoitustaso

$\left.{ }^{2}\right) \mathrm{v}=$ voimakas lannoitustaso 
Taulukko 2. Eri Talviperunalajikkeiden keskimääräiset ominaispainot ja ominaispainojakautumat. Painomäärältään suurin ominaispainoluokka alleviivattu taulukossa.

\begin{tabular}{|c|c|c|c|c|c|c|}
\hline Lajike ja lannoitustaso & $\begin{array}{l}\text { Keski- } \\
\text { määräinen } \\
\text { om.p. }\end{array}$ & $<1065$ & $\begin{array}{l}1065- \\
1075-\end{array}$ & $\begin{array}{l}1075- \\
1085-\end{array}$ & $\begin{array}{l}1085- \\
1095-\end{array}$ & $>1095$ \\
\hline & & $\%$ & $\%$ & $\%$ & $\%$ & $\%$ \\
\hline Alfa $\mathrm{n}^{1}$ ) & 1.092 & & 2.4 & 11.6 & 34.9 & 51.0 \\
\hline Alfa $v^{2}$ ) & 1.084 & 2.0 & 7.3 & 34.3 & 43.3 & $\overline{13.0}$ \\
\hline Bintje $\mathrm{n}$ & 1.091 & 1.1 & 4.7 & 26.1 & 50.0 & 18.4 \\
\hline Bintje $v$ & 1.077 & 2.2 & 19.8 & 62.6 & 15.2 & \\
\hline Milva $\mathrm{n}$ & 1.094 & & & 4.5 & 15.7 & 79.7 \\
\hline Milva $\mathrm{v}$ & 1.092 & & 1.9 & 7.6 & 40.5 & 50.0 \\
\hline Patrones n & 1.089 & 1.7 & 5.9 & 22.4 & 43.0 & 27.0 \\
\hline Patrones v & 1.082 & 2.3 & 14.5 & $\underline{48.0}$ & $\overline{30.9}$ & 4.3 \\
\hline Realta $n$ & 1.096 & 1.9 & 5.1 & 36.9 & $\underline{49.4}$ & 7.7 \\
\hline Realta $\mathbf{v}$ & 1.080 & 4.5 & 18.0 & 50.2 & $\overline{27.3}$ & \\
\hline Rekord n & 1.093 & & 2.0 & 13.3 & 40.4 & $\underline{44.3}$ \\
\hline Rekord $\mathrm{v}$ & 1.080 & & 11.1 & 45.0 & 38.2 & 5.7 \\
\hline Tombola $\mathrm{n}$ & 1.085 & & 8.9 & $\underline{43.0}$ & 40.5 & 7.6 \\
\hline Tombola $\mathrm{v}$ & 1.078 & 0.8 & 26.9 & 64.7 & 7.6 & \\
\hline
\end{tabular}

1) $\mathrm{n}=$ normaali lannoitustaso

2) $\mathrm{v}=$ voimakas lannoitustaso

Maku ja ja uhois u us. Kustakin lajikkeesta tehtiin maun ja jauhoisuuden arvostelu 2-3 ominaispainoluokasta ns. moitteettoman ruokaperunan osuuden selvittämiseksi. Useimmilla lajikkeilla oli molemmilla lannoitustasoilla moitteettoman ruokaperunan alarajana ominaispaino 1.075, josta lähtien peruna oli sekä maultaan että jauhoisuudeltaan moitteetonta (varhaisperunalajikkeet Dore, Ersteling, Sirtema, talviperunalajikkeet Alfa, Bintje, Milva, Rekord ja Tombola). Poikkeuksen tekivät Ostara, Siikli ja Patrones, joiden ominaispainon täytyi olla $>1.085$, jotta perunat olisivat täyttäneet moitteettomalle ruokaperunalle asetetut vähimmäisvaatimukset. Realtalla oli normaalilla lannoitustasolla ominaispainoluokka 1.075-1.085 moitteetonta. Voimakkaalla lannoitustasolla Realta oli jauhoisuudeltaan niin paljon huonompaa, ettei korkeinkaan ominais- 


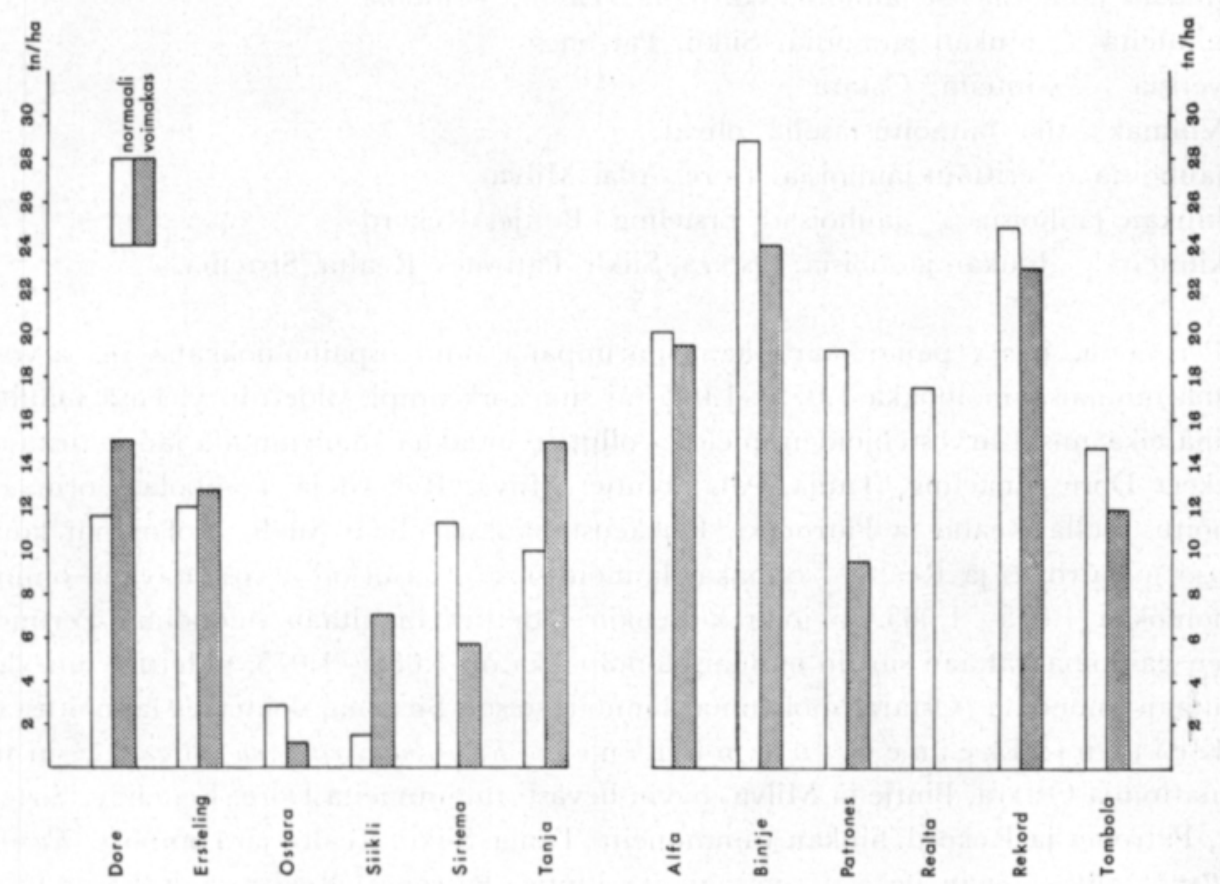

Kuva 2. Moitteettoman ruokaperunan määrät eri perunalajikkeista kokoluokasta $35-55 \mathrm{~mm}$ normaalilla ja voimakkaalla lannoitustasolla.

painoluokka, >1.095, täyttänyt jauhoisuudelle asetettua minimivaatimusta »hiukan jauhoinen». Realtasta ei näin ollen saatu lainkaan moitteetonta ruokaperunaa voimakkaalta lannoitustasolta. Realta osoittautui siten tutkituista lajikkeista herkimmäksi lannoitukselle moitteettoman ruokaperunan alarajan pysyessä muilla lajikkeilla samana molemmilla lannoitustasoilla.

Eri lajikkeiden moitteettoman ruokaperunan osuudet \%:na kokoluokasta $35-55 \mathrm{~mm}$ sekä määrinä sadosta (tn/ha) on esitetty taulukoissa 3 ja 4 . Moitteettoman ruokaperunan prosenttiset määrät vaihtelevat $0-98 \%$ moitteettoman ruokaperunan sadon vaihdellessa vastaavasti $0-24 \mathrm{tn} /$ ha (kuva 2).

Lannoituksen ominaispainoa alentava vaikutus tulee näkyviin kaikilla lajikkeilla moitteettoman ruokaperunan prosentuaalisen määrän alenemisena. Kun lannoitus lisäsi kokonaissatoa, oli moitteettoman ruokaperunan sadon määrä ( $\operatorname{tn} / \mathrm{ha})$ varhaisperunalajikkeilla Sirtemaa lukuunottamatta suurempi voimakkaalla lannoitustasolla kuin normaalilla. Talviperunalajikkeilla ei lannoituksen aiheuttama sadon lisäys kompensoinut lannoituksen ominaispainoa alentavaa vaikutusta, ja siitä johtuvaa laadun huononemista, joten näistä saatiin normaalilla lannoituksella enemmän moitteetonta ruokaperunaa (tn/ha) kuin voimakkaalla lannoituksella.

Pidettäessä painomäärältään suurimman ominaispainoluokan makua ja jauhoisuutta ko. lajikkeelle ominaisena makuna ja jauhoisuutena olivat normaalilla lannoitustasolla, 
jauhoisia - erittäin jauhoisia: Dore, Ersteling, Alfa, Bintje, Milva, Realta, Rekord hiukan jauhoisia - jauhoisia: Sirtema, Tanja, Tombola

kiinteitä — hiukan jauhoisia: Siikli, Patrones

vetisiä — kiinteitä: Ostara

Voimakkaalla lannoitustasolla olivat:

jauhoisia - erittäin jauhoisia: Dore, Alfa, Milva

hiukan jauhoisia - jauhoisia: Ersteling, Bintje, Rekord

kiinteitä — hiukan jauhoisia: Ostara, Siikli, Patrones, Realta, Sirtema.

Perunoita, joista painomäärältään suurimpana ominaispainoluokkana oli arvosteltavana ominaispainoluokka 1.075-1.085 tai sitä korkeampi, pidettiin yleensä maultaan hyvinä eikä niissä arvostelijoiden mielestä ollut sivumakua (molemmilla lannoitustasoilla lajikkeet Dore, Ersteling, Tanja, Alfa, Bintje, Milva, Rekord ja Tombola, normaalilla lannoitustasolla Realta ja Patrones). Poikkeustapauksia olivat Siikli (molemmat lannoitustasot), Patrones ja Realta (voimakas lannoitustaso), joista oli arvosteltavana ominaispainoluokka 1.075-1.085, ja joita kuitenkin pidettiin maultaan huonoina. Perunoita, joiden painomäärältään suurin ominaispainoluokka oli $1.065-1.075$, pidettiin niin ikään maultaan huonoina (Ostara, molemmat lannoitustasot, Sirtema, voimakas lannoitustaso).

$\mathrm{Ke}$ ito njälkein e n $\mathrm{t}$ u m m u in e n. Kuorittuna keitettynä olivat täysin tummumattomia Ostara, Bintje ja Milva, hyvin lievästi tummuneita Dore, Ersteling, Sirtema, Alfa, Patrones ja Rekord, hiukan tummuneita Tanja, Siikli, Realta ja Tombola. Kuorineen keitettynä olivat hyvin lievästi tummuneita Bintje, Patrones, Realta ja Rekord, hiukan tummuneita Dore, Ersteling, Ostara, Tanja, Siikli ja Alfa, pahasti tummuneita Sirtema, Milva ja Tombola.

Lannoituksen kaksinkertaistaminen ei tulosten mukaan vaikuttanut keiton jälkeiseen tummumisen esiintymiseen, mikä johtunee siitä, että typen ja kalin suhde oli sama kummallakin lannoitustasolla.

Rik ki ki e h u m i n e n. Vedessä kuorineen keitettynä pysyivät ehjinä kaikki varhaisperunalajikkeet. Talviperunalajikkeista olivat ehjiä Alfa, Patrones, Realta ja Tombola molemmilta lannoitustasoilta. Bintjestä ja Rekordista oli yksi kymmenestä mukulasta hiukan rikki muiden ollessa täysin ehjiä. Milvasta olivat normaalin lannoitustason perunat kaikki hajalla ja voimakkaan lannoitustason perunoista neljä kymmenestä hajosi.

$\mathrm{S}$ ä i l y v y s kuorit t u na. Kuorittuna säilyvyyden tutkimista varten perunat käsiteltiin $30 \mathrm{~s}$ ajan $0.25 \%$ :sella $\mathrm{NaHSO}_{3}$-liuoksella ja varastoitiin $4-6^{\circ} \mathrm{C}$ :ssa. Säilyvyys vaihteli $1-5$ vrk lajikkeesta riippuen. Varhaisperunalajikkeista säilyivät $4-5$ vrk tummumattomina Ostara, Siikli, Sirtema ja Tanja Doren ja Erstelingin säilyessä 2-3 vrk. Talviperunasäilykkeistä säilyivät Alfa, Bintje ja Tombola 2 vrk, kun taas Patrones ja Rekord säilyivät vain 1 vrk:n väriltään moitteettomina.

Lannoitustasojen väliset makuerot tutkittiin erotustestillä. Makuero lannoitustasojen välillä todettiin lajikkeilla Siikli, Tanja, Realta ja Patrones, mutta ei sen sijaan muilla lajikkeilla (Dore, Ersteling, Ostara, Sirtema, Alfa, Bintje, Milva, Rekord ja Tombola). Niissä tapauksissa, joissa makuero havaittiin, pitivät arvostelijat yleensä normaalin lannoitustason perunoita maultaan parempina kuin voimakkaan lannoitustason perunoita. 
Taulukko 3. Moitteettoman ruokaperunan määrät eri talviperunalajikkeista kokoluokasta $35-55 \mathrm{~mm}$.

Lajike ja lannoitustaso

Moitteettoman ruokaperunan määrä

$\% \quad \operatorname{tn} /$ ha

$\begin{array}{ll}\text { Alfa } & \left.\mathrm{n}^{1}\right) \\ \text { Alfa } & \mathrm{v}^{2} \text { ) } \\ \text { Bintje } & \mathrm{n} \\ \text { Bintje } & \mathrm{v} \\ \text { Milva } & \mathrm{n} \\ \text { Milva } & \mathrm{v} \\ \text { Patrones } & \mathrm{n} \\ \text { Patrones } & \mathrm{v} \\ \text { Realta } & \mathrm{n} \\ \text { Realta } & \mathrm{v} \\ \text { Rekord } & \mathrm{n} \\ \text { Rekord } & \mathrm{v} \\ \text { Tombola } & \mathrm{n} \\ \text { Tombola } & \mathrm{v} \\ & \end{array}$

1) $\mathrm{n}=$ normaali lannoitus

2) $\mathbf{v}=$ voimakas lannoitus

3) voimakas rikkikiehuminen rajoittaa käyttöä

Taulukko 4. Moitteettoman ruokaperunan määrät eri varhaisperunalajikkeissa kokoluokasta $35-55 \mathrm{~mm}$.

Lajike ja lannoitustaso

Moitteettoman ruokaperunan määrä

$\%$ tn/ha

$\begin{array}{llrr}\text { Dore } & \left.\mathrm{n}^{1}\right) & 89.1 & 11.6 \\ \text { Dore } & \left.\mathrm{v}^{2}\right) & 86.6 & 15.1 \\ \text { Ersteling } & \mathrm{n} & 89.4 & 12.0 \\ \text { Ersteling } & \mathrm{v} & 72.2 & 12.8 \\ \text { Ostara } & \mathrm{n} & 1.4 & 2.9 \\ \text { Ostara } & \mathrm{v} & 0.5 & 1.2 \\ \text { Siikli } & \mathrm{n} & 15.1 & 1.5 \\ \text { Siikli } & \mathrm{v} & 4.1 & 7.0 \\ \text { Sirtema } & \mathrm{n} & 55.2 & 11.3 \\ \text { Sirtema } & \mathrm{v} & 27.9 & 5.7 \\ \text { Tanja } & \mathrm{n} & 96.3 & 10.0 \\ \text { Tanja } & \mathrm{v} & 84.8 & 15.0\end{array}$

1) $\mathbf{n}=$ normaali lannoitus

$\left.{ }^{2}\right) \mathrm{v}=$ voimakas lannoitus 


\section{Tarkastelua}

Käsillä olevassa tutkimuksessa on ominaispainon ja perunan maun sekä jauhoisuuden välistä riippuvuutta käytetty hyväksi määritettäessä ns. moitteettoman ruokaperunan osuutta. Menettelyä voidaan verrata JoHAnssonin (1966) tai SMAK-arvostelussa (Kungliga lantbrukstyrelsens kungörelser, 1964) käytettyyn tapaan laskea vetisten perunoiden määrä ja käyttää tätä yhtenä laatua kuvaavana parametrina.

Ominaispainolajittelu niin moneen luokkaan kuin tässä tutkimuksessa on tarkoituksenmukaista vain tutkimustyössä. Perunan ominaispainon ja sen muiden ominaisuuksien välistä riippuvuutta voitaisiin käyttää kuitenkin hyväksi myös teollisessa ruokaperunajalosteiden valmistuksessa. On osoitettu, että korkean ominaispainon (suuri kuiva-aineja tärkkelyspitoisuus) perunoista on taloudellisesti edullisempaa valmistaa rasvassa kyFsennetyt perunajalosteet (ranskalaiset perunat, lastut) (WhIteman ja Wright 1949). Lisäksi korkean ominaispainon perunoista saadaan laadultaan ja maittavuudeltaan parempia ranskalaisia perunoita kuin alhaisen ominaispainon perunoista, joista tehdyt ranskalaiset perunat ovat nahkeita ja vetisiä (KIRCKPATRICK ym. 1956). Voitaisiin myös ajatella, että pakastettu perunasose tulee korkean ominaispainon perunoista parempi kuin alhaisen ominaispainon perunoista, joista valmistetuissa soseissa sulatuksen jälkeen jää runsaasti vettä sitoutumatta. Tölkitetyn perunan kuiva-ainepitoisuus taas ei saa olla suuri, koska perunat tällöin hajoavat helposti. Jalosteiden raaka-aineen valinnassa voitaisiin kiinnittää näin ollen huomiota perunan ominaispainoon tai sen kuiva-aine- ja tärkkelyspitoisuuteen. Ominaispainolajittelu esim. kahteen eri ominaispainoluokkaan tarjoaisi mahdollisuuden saada jalosteisiin tasalaatuista materiaalia ja parantaa niiden laatua.

Moitteettoman ruokaperunan osuutta määritettäessä käytettiin attribuutteihin perustuvaa maun ja jauhoisuuden arvostelua. Tällöin todettiin, että useimmilla lajikkeilla oli molemmilla lannoitustasoilla ominaispainorajana 1.075, jota suuremman ominaispainon peruna oli sekä maultaan että jauhoisuudeltaan moitteetonta. Poikkeuksena olivat Ostara, Siikli ja Patrones, jotka olivat maultaan ja jauhoisuudeltaan moitteettomia vasta ominaispainosta $>1.085$ lähtien. Realtasta taas olivat normaalilla lannoitustasolla ominaispainoltaan $\overline{>} 1.075$ olevat perunat moitteettomia, mutta voimakkaalla lannoituksella ei korkeinkaan ominaispainoluokka $(>1.095)$ täyttänyt moitteettomalle ruokaperunalle asetettuja vaatimuksia.

Tutkittaessa triangelitestillä lannoituksen aiheuttamia maun muutoksia, kävi selville, että yleensä niihin lajikkeisiin, jotka olivat sekä maultaan että jauhoisuudeltaan moitteettomia ominaispainosta 1.075 lähtien, ei lannoituksen kaksinkertaistaminen aiheuttanut triangelitestillä todettavaa maun muutosta. Makuero eri lannoituksella viljeltyjen perunoiden välillä todettiin sen sijaan Ostaraa lukuunottamatta niillä lajikkeilla, joiden moitteettoman ruokaperunan alaraja oli 1.085 tai sitä korkeampi (Siikli, Patrones ja Realta). Molemmilla menetelmillä saatujen samansuuntaisten tulosten voidaan katsoa osoittavan k.o. lajikkeiden heikompaa laatua muihin lajikkeisiin verrattuna.

Tutkimuksessa saavutettiin kuoritun perunan säilyvyydessä verraten lyhyet säilyvyysajat. Perunat saadaan kuitenkin säilymään pitempäänkin väriltään moitteettomana, jos sulfiittiliuoksen konsentraatiota lisätään. 


\section{Yhteenveto}

Tutkimuksessa selvitettiin kahdella eri lannoitustasolla viljellyn 14 perunalajikkeen ruokaperunaominaisuudet. Kokeissa olivat varhaisperunalajikkeina Dore, Ersteling, Ostara, Siikli, Sirtema ja Tanja sekä talviperunalajikkeina Alfa, Bintje, Milva, Patrones, Realta, Rekord ja Tombola.

Laadun kriteerinä on pidetty ominaispainoa, makua, jauhoisuutta, moitteettoman ruokaperunan määrää, keitonjälkeistä tummumista ja rikkikiehumista (ElLALA ym. 1971).

Moitteettoman ruokaperunan osuus vaihteli eri lajikkeilla $0-98 \%$. Moitteettoman ruokaperunan määrä sadosta vaihteli $0-28 \mathrm{tn} / \mathrm{ha}$. Lannoituksen ominaispainoa alentava vaikutus ilmeni kaikilla lajikkeilla moitteettoman ruokaperunan prosentuaalisen osuuden alenemisena. Moitteettoman ruokaperunan sadon määrä (tn/ha) oli varhaisperunalajikkeilla Sirtemaa lukuunottamatta suurempi voimakkaalla lannoituksella kuin normaalilla. Talviperunalajikkeilla ei lannoituksen aiheuttama sadon lisäys kompensoinut lannoituksen ominaispainoa alentavaa vaikutusta, joten niistä saatiin normaalilla lannoituksella enemmän moitteetonta ruokaperunaa kuin voimakkaalla lannoituksella.

Rikkikiehumista esiintyi haitallisessa määrin ainoastaan Milvassa, jossa hajoaminen oli niin voimakasta, että se rajoittanee k.o. lajikkeen käyttöä ruokaperunana. Sen sijaan lajike voi olla käyttökelpoinen jalosteisiin, joissa korkea kuiva-ainepitoisuus on eduksi ja joissa rikkikiehuminen ei ole esteenä. Perunat säilyivät $0.25 \%$ :sella $\mathrm{NaHSO}_{3}$-liuoksella käsittelyn jälkeen $1-5$ vrk tummumattomina lajikkeesta riippuen.

Lannoituksen todettiin aiheuttavan makueroa vain kahteen varhaisperunalajikkeeseen (Siikli, Tanja) ja kahteen talviperunalajikkeeseen (Realta, Patrones). Muilla lajikkeilla makueroa ei triangelitestiä käyttäen todettu.

\section{KIRJALLISUUTTA}

Ellala, A., VAnhanen, L. \& Kurkela, R. 1971. Typpi- ja kalilannoituksen vaikutus ruokaperunan laatuun. J. Sci. Agric. Soc. Finland 43: 63.

Itä-Suomen Raakasokeritehdas Oy:n perunanviljelykokeet. Tulokset 1968. 51 p. Kotka.

Joнаnsson, O. 1966. Rapport från pågående växtnäringsförsök med potatis. I kväve och fosforsgödsling. Akt. Lantbr. högsk. 13: 1 .

Kirckpatrick, M. E., Heinze, P. H., Mountjoy, B. M. \& Falatko, C. E. 1956. French frying quality of potatoes as influenced by cooking methods, storage, conditions, and specific gravity of tubers. U. S. Dept. Agr. Tech. Bull. 1142.

Kunkel. R., Greogory, J., Binkley, A. M. 1951. Mechanical separation of potatoes into specificgravity. groups shows promise for the potato chip industry. Am. Potato J. 28: 690 .

Kungl. lantbruksstyrelsens kungörelser m. m. 1964, $\mathrm{Nr} 9$, angående kvalitetsundersökning av matpotatis vid statens centrala frökontrollanstalt och Svensk matpotatiskontroll.

Talburt, W. F., Sмiтh, O. 1967. Potato processing. Westport, Connecticut, p. 291.

Whiteman, T. M. and Wright, R. C. 1949. Effects of variety, specific gravity of tubers and cooking fat on the quality and yield of potato chips. Potato chipper 9, N. 3, 18, 20, 22, 26, 28, 32, 34, 38 . (Ref. Talburt, W. F. \& Smith, O. 1967). 